\title{
OS SENTIDOS DO ENSINO DE SOCIOLOGIA: O QUE DIZEM EGRESSOIAS DA LICENCIATURA EM CIENCIAS SOCIAIS DA UFSC?
}

\author{
The senses of teaching Sociology: What do the graduates of Social Sciences of \\ UFSC say?
}

\author{
Marcelo Cigales ' \\ Inaê label Barbosa ${ }^{2}$ \\ Sabrina de Freitas Smialoski ${ }^{3}$ \\ Beatriz Melchioretto Claudino dos Santos ${ }^{4}$
}

\section{Resumo}

Este artigo evidencia os sentidos atribuídos ao ensino da Sociologia, por egressos/as do curso de licenciatura em Ciências Sociais da Universidade Federal de Santa Catarina (UFSC). A metodologia baseouse no uso de entrevistas estruturadas, realizadas junto a 18 egressos/as, sendo que apenas oito haviam tido contato com o ensino da Sociologia depois de formados/as. Como referencial teórico, utilizamos o conceito de campo de Bourdieu, com o intuito de compreender os diferentes sentidos atribuídos ao ensino da Sociologia nos campos político, acadêmico e escolar, comparando-os com os sentidos apresentados nas falas dos/as entrevistados/as. Além de se apresentar de forma multifacetada nos diferentes campos analisados, os sentidos do ensino da disciplina são vinculados, na visão dos/as professores/as, principalmente: (1) a formação de sujeitos críticos e conscientes do mundo em que vivem; (2) a afirmação da Sociologia enquanto conhecimento científico e fornecedor de ferramentas analíticas de interpretação do mundo social, e (3) a promoção da transformação social e a militância.

Palavras-chave: Ensino de Sociologia; sentido pedagógico; professores egressos; UFSC.

\begin{abstract}
This article evidences the meanings attributed to the teaching of Sociology, by graduates of the degree course in Social Sciences in the Federal University of Santa Catarina (UFSC). The methodology was based on the use of structured interviews, carried out with 18 graduates, and only eight had had con-
\end{abstract}

\footnotetext{
${ }^{1}$ Professor adjunto do Departamento de Sociologia da Universidade de Brasilia (UnB). Pósdoutorando em Sociologia e Ciência Política pela Universidade Federal de Santa Catarina (UFSC). Email: marcelo.cigales@unb.br

2 Licenciada em Ciências Sociais pela Universidade Federal de Santa Catarina. Email: inaeib@outlook.com

${ }^{3}$ Licenciada em Ciências Sociais pela Universidade Federal de Santa Catarina. Email: sabrina.smialoski@hotmail.com

${ }^{4}$ Graduanda em Ciências Sociais pela Universidade Federal de Santa Catarina. Email: biaclaudiono190@gmail.com
} 
Os sentidos do ensino de Sociologia: o que dizem egresso/as da licenciatura em Ciências Sociais da UFSC | Marcelo Cigales, Inaê label Barbosa, Sabrina de Freitas Smialoski e Beatriz Melchioretto Claudino dos Santos

tact with the teaching of Sociology after graduating. As a theoretical reference, we use the concept of field from Pierre Bourdieu, in order to understand the different meanings attributed to the teaching of Sociology, in the political, academic and scholar fields, comparing them with the meanings presented in the speeches of those interviewed. In addition to being presented in a multifaceted way in the different fields analyzed, the teaching senses of the discipline are linked, in the view of the teachers, mainly: (1) the formation of critical and conscious subjects of the world in which they live; (2) the affirmation of Sociology as scientific knowledge and provider of analytical tools of interpretation of the social world, and (3) the promotion of social transformation and militancy.

Keywords: Teaching of sociology; Pedagogical sense; Teachers graduates; UFSC. 
Os sentidos do ensino de Sociologia: o que dizem egresso/as da licenciatura em Ciências Sociais da UFSC | Marcelo Cigales, Inaê label Barbosa, Sabrina de Freitas Smialoski e Beatriz Melchioretto Claudino dos Santos

\section{Introdução}

O ensino de Sociologia no Brasil possui uma característica de presença e ausência no currículo da educação básica. A última década, compreendida entre os anos de 2008 e 2018, foi significativa em relação a presença da disciplina, reflexo das lutas político-acadêmicas das décadas anteriores que trouxeram para o cenário político os Projetos de Lei (PL) do deputado Padre Roque (PL 3.178/1997) e do deputado Ribamar Alves (PL 1.641/2003), este último sendo aprovado em 2008 (Lei 11.684/2008), alterando assim, o artigo 36, parágrafo $1^{\circ}$ da Lei de Diretrizes e Bases da Educação Nacional (LDBEN) de 1996, e instituindo a Filosofia e a Sociologia como disciplinas obrigatórias no Ensino Médio.

A medida legislativa alavancou as pesquisas dentro das universidades e incentivou a entrada da Sociologia em dois programas educacionais (o Programa Institucional de Bolsa de Iniciação à Docência - PIBID e o Programa Nacional do Livro Didático - PNLD), além da abertura de dezenas de cursos de licenciatura em Ciências Sociais, de linhas de pesquisa na Pósgraduação e do Mestrado profissional em Ensino de Ciências Sociais. No entanto, a reforma do Ensino Médio, aprovada sob Medida Provisória (MP 746 de 2016), retirou a obrigatoriedade da Sociologia como disciplina escolar ao transformá-la em "conteúdo e prática", fechando assim, mais um ciclo de descontinuidades no currículo da educação básica no Brasil (GESTEIRA, 2018; BODART \& TAVARES, 2018; BRUNETTA \& CIGALES; 2018; SILVA \& GONÇALVES, 2017; CIGALES, 2019)5 .

Quando se considera a presença (ou ausência) da Sociologia no currículo da Educação Básica, uma questão se torna central: qual o sentido de ensinar (e aprender) Sociologia? Assim, neste artigo buscamos compreender quais sentidos são atribuídos por professores/as formados/as em Ciências Sociais na UFSC 6 ao ensino de Sociologia na Educação Básica.

\footnotetext{
${ }^{5}$ É de destacar que a BNCC em sua terceira versão não fala em "conteúdos e práticas" em relação ao ensino de Sociologia, dando continuidade ao seu caráter disciplinar. No entanto, dado a flexibilização dos itinerários formativos, na prática dificilmente a Sociologia conseguirá se firmar a nível nacional como uma disciplina escolar.

${ }^{6}$ O Curso de Ciências Sociais se originou da Faculdade Catarinense de Filosofia, criada em 1950. Conforme Oliveira (2018, p. 118) "Apesar de não serem as primeiras cátedras nesta área, encontra-se aí o gérmen para o
} 
Os sentidos do ensino de Sociologia: o que dizem egresso/as da licenciatura em Ciências Sociais da UFSC | Marcelo Cigales, Inaê label Barbosa, Sabrina de Freitas Smialoski e Beatriz Melchioretto Claudino dos Santos

Cabe destacar que esta pesquisa faz parte de um projeto mais amplo, que busca analisar o perfil de egressos/as da licenciatura com objetivo de compreender suas trajetórias sociais, escolares e acadêmicas ${ }^{7}$. A metodologia deu-se por meio de entrevistas estruturadas, que foram realizadas junto a 18 egressos formados entre os anos de 1990 e 2016. As entrevistas ocorreram entre os meses de maio e setembro de 2018, sendo posteriormente transcritas e analisadas pelo conjunto de pesquisadores/as que fazem parte do Núcleo de Estudos da Educação e Juventudes Contemporâneas (NEJUC) da UFSC.

Constatamos que das 18 entrevistas, apenas oito haviam respondido as questões do bloco sobre o "sentido do ensino de Sociologia". A baixa adesão a essa resposta deu-se em função da sua vinculação, no questionário, àqueles/as egressos/as que tiveram contato com o magistério. Portanto, uma das nossas primeiras constatações é que parte considerável do público entrevistado não atuou com o ensino da Sociologia na Educação Básica. Tal fato pode ser reflexo tanto das políticas de incentivo a Pós-graduação, que alargou a vida acadêmica da geração de formados/as a partir dos anos 2000, assim como das péssimas condições de trabalho que se defrontam os/as professores/as no Brasil, fazendo com que os/as egressos/as da licenciatura optem por seguir estudando ou migrem para outras profissões - ainda mais no caso da Sociologia que possui uma baixa carga horária no currículo da Educação Básica (KATREN, MARCASSA, 2014; LENNERT, 2011; BODART, SAMPAIO, 2016; BODART, 2018).

Cabe destacar que os sentidos atribuídos ao ensino da Sociologia são múltiplos, se relacionam diretamente com o projeto de sociedade idealizado por diferentes grupos sociais, e perpassam diversos campos, dos quais des-

\footnotetext{
desenvolvimento das ciências sociais no estado, uma vez que esta faculdade posteriormente foi incorporada à Universidade Federal de Santa Catarina (UFSC), possibilitando o surgimento de um curso próprio na década de 1970".

${ }^{7} \mathrm{O}$ projeto de pesquisa intitulado "Após a licenciatura em Ciências Sociais na UFSC: trajetórias e perfis de egressos" buscou organizar uma proposta coletiva de estudo qualitativo, a ser conduzida no âmbito do Núcleo de Estudos da Educação e Juventudes Contemporâneas (NEJUC), visando reconstruir as trajetórias sociais, escolares e acadêmicas. O projeto foi desenvolvido entre os anos de 2017 e 2018, sob a supervisão dos professores Amurabi Oliveira e Eduardo Bonaldi.
} 
Os sentidos do ensino de Sociologia: o que dizem egresso/as da licenciatura em Ciências Sociais da UFSC | Marcelo Cigales, Inaê label Barbosa, Sabrina de Freitas Smialoski e Beatriz Melchioretto Claudino dos Santos

tacamos o político, o acadêmico e o escolar, que, na nossa perspectiva, juntos constituem o campo educacional no Brasil. Assim, evidenciar os sentidos atribuídos ao ensino da Sociologia nesses espaços é relevante para compreendermos as disputas sobre as diferentes visões e representações sobre a função da Sociologia no currículo escolar.

Para problematizar os sentidos pedagógicos da Sociologia na Educação Básica, utilizamos a divisão entre a ciência educacional e a teoria pedagógica, realizada por Émile Durkheim, atribuindo um sentido prático a última, visto que sua função é "dizer como as coisas deveriam ser". Em suas palavras:

[...] as teorias chamadas pedagógicas são especulações de gênero muito diverso. Seu objetivo não é o de descrever ou explicar o que é, ou o que tem sido, mas de determinar o que deve ser. Não estão orientadas nem para o presente nem para o passado, mas para o futuro. Não se propõe a exprimir fielmente certas realidade, mas a expor preceitos de conduta. Elas não nos dizem: "eis o que existe e por que existe". Mas, sim: "eis o que será preciso fazer" (DURKHEIM, s/d, p. $50)$.

Pensamos que o caráter pedagógico da Sociologia não mereceu, até então, devida atenção do campo acadêmico das Ciências Sociais no Brasil. Talvez porque as configurações do campo acadêmico brasileiro e, consequentemente, a formação de professores/as, estiveram mais voltados a pensar a ciência da educação do que a teoria pedagógica, negligenciando assim, o caráter prático e normativo da disciplina.

Utilizamos o conceito de campo de Bourdieu como categoria analitica para compreender os sentidos do ensino da Sociologia no Brasil. Entendemos o conceito de campo como um espaço simbólico estruturado por determinados agentes (indivíduos e instituições) que possuem uma relação assimétrica de poder, determinado a partir das posições sociais caracterizada pelo acúmulo de diferentes capitais (econômico, cultural, social e simbólico) e de um habitus, capaz de orientar as ações desses agentes e de dotar sentido às representações sobre os produtos culturais e às práticas sociais legitimadas dentro desse espaço. Em sintese, o campo é um espaço social relativamente autônomo que possui suas próprias regras, premiações e san- 
Os sentidos do ensino de Sociologia: o que dizem egresso/as da licenciatura em Ciências Sociais da UFSC | Marcelo Cigales, Inaê label Barbosa, Sabrina de Freitas Smialoski e Beatriz Melchioretto Claudino dos Santos

ções. Seus agentes compartilham um determinado habitus, que se constitui de sistemas de pensamento e representações sobre o mundo social, determinando suas maneiras de pensar e agir nesses diferentes espaços (BOURDIEU, 1996; 2009; 2014).

Além desta introdução, o artigo se divide da seguinte forma: na próxima seção apresentamos e discutimos os principais estudos realizados sobre os sentidos da Sociologia no Brasil, tendo como foco os discursos legislativos no campo politico, os documentos curriculares produzidos por especia$\operatorname{listas}^{8}$ na área que orientam o ensino da Sociologia no campo acadêmico, e a visão de estudantes e professores/as da rede pública de ensino no campo escolar. A partir dessa discussão, no tópico seguinte, analisamos as falas dos/as entrevistados/as, buscando categorizá-las a partir dos principais sentidos atribuídos ao ensino da Sociologia. Esperamos que esse trabalho avance na discussão sobre o sentido pedagógico da Sociologia, contribuindo para a compreensão do seu papel da educação básica.

\section{Os diferentes sentidos atribuídos a Sociologia no campo educacional}

Temos como hipótese que os sentidos do ensino de Sociologia no Brasil são multifacetados pois estão vinculados, em cada momento histórico, a determinados projetos civilizacionais (ELIAS, 1993) e se caracterizam pelos diferentes anseios e representações dos diferentes campos sociais que, reunidos, constituem o campo educacional. Assim, nossa intenção nesta seção é compreender através da literatura sobre o ensino de Sociologia, quais os

\footnotetext{
${ }^{8}$ Destaca-se os PCNEM, na área de Ciências Humanas e suas Tecnologias, do qual está presente a Sociologia, os responsáveis técnicos foram: Avelino Pereira (Doutor em História); Adir Carvalho Filho (Doutor em Filosofia), Catia Silva (Doutora em Geografia), Circe Bittencourt (Doutora em História Social), Janecleide Aguiar (Doutora em Psicologia Social), Leila Barbosa Safadi (não foram encontradas informações sobre a autora), Sonia Elza Peixoto Chiara Botelho (não foram encontradas informações sobre a autora), com a colaboração de Dirceu Castilho Heloísa Fesch Menandro Roberto Macedo. Os OCNEM, por sua vez tiveram a coordenação na área de Sociologia, com os professores Amaury Cesar Moraes (Doutor em Educação), Nelson Dacio Tomazi (Doutor em História) e Elizabeth Guimarães (Doutora em Educação), com as leituras críticas de Ileizi Silva (Doutora em Sociologia) Pedro Conteratto (Mestrado em Ciências Sociais), e Pedro Tomaz de Oliveira Neto (Especialista em Ciência Política). A BNCC, teve a participação de vários especialistas da área, contanto com Haydée Caruso (Doutora em Antropologia), Fabiano Farias de Souza (Doutor em História), Ileizi Silva (Doutora em Sociologia), e Marcos Antonio Silva (Mestre em Educação).
} 
Os sentidos do ensino de Sociologia: o que dizem egresso/as da licenciatura em Ciências Sociais da UFSC | Marcelo Cigales, Inaê label Barbosa, Sabrina de Freitas Smialoski e Beatriz Melchioretto Claudino dos Santos

sentidos atribuídos para a disciplina, com ênfase para o campo político, acadêmico e escolar.

Entendemos o primeiro como o espaço da política institucional, onde se discute a partir dos anos 1990, a inclusão da Sociologia como disciplina escolar no currículo do Ensino Médio brasileiro; o segundo como o espaço de produção do conhecimento nas Instituições de Ensino Superior (IES), com seus e suas acadêmicos/as, linhas de pesquisa, publicações e centros de formação de professores/as; e o terceiro, mais especificamente voltado para aqueles agentes que vivem o currículo escolar, estudantes do Ensino Médio e professores e professoras da disciplina. Doravante, é na interface desses espaços que se disputam os sentidos do ensino da Sociologia, pois é por meio deles que, por um lado, os conteúdos e programas curriculares são pensados, negociados e direcionados para as instituições educacionais, e por outro, são vividos e ressignificados pelos agentes nas práticas cotidianas, mediados pelas condições objetivas e subjetivas do espaço escolar. Também é importante salientar que no interior desses espaços os sentidos da Sociologia também são multifacetados, porém, neste trabalho, optamos por fazer uma sintese das principais discussões em cada um desses campos sociais, com o intuito de compreender, as principais discussões sobre o sentido pedagógico da Sociologia no país.

\section{Campo político}

Em relação aos sentidos atribuídos ao ensino de Sociologia no campo político, o trabalho de Azevedo (2014) analisa os discursos produzidos pelos parlamentares nas duas Casas do Congresso Nacional (a Câmara dos Deputados e o Senado Federal), durante a tramitação dos PL 3.178/1997 e PL 1.641/2003, a fim de observar as expectativas desses agentes sobre o ensino da disciplina da Educação Básica. Segundo o autor, "entre os argumentos favoráveis à obrigatoriedade da disciplina, destacam-se os objetivos de boa formação da juventude brasileira e construção de uma sociedade democrática e cidadã" (AZEVEDO, 2014, p. 08). 
Os sentidos do ensino de Sociologia: o que dizem egresso/as da licenciatura em Ciências Sociais da UFSC | Marcelo Cigales, Inaê label Barbosa, Sabrina de Freitas Smialoski e Beatriz Melchioretto Claudino dos Santos

Resumidamente, Azevedo afirma que esses argumentos favoráveis podem ser organizados em cinco eixos que colocam o papel da disciplina como instrumento: (1) para o desenvolvimento do senso crítico, (2) de formação para a cidadania, (3) para a transformação social, (4) para introduzir a juventude no mundo do trabalho, e (5) para a "formação humanística" (devido aos conteúdos próprios da Sociologia que não são abordados por outras disciplinas) (AZEVEDO, 2014).

Já o trabalho de Gesteira (2018) analisa os discursos de representantes de instituições políticas (senadores, deputados federais e membros do Conselho Nacional de Educação) sobre a função da Sociologia enquanto disciplina escolar em debates realizados no Congresso Nacional ${ }^{9}$. Partindo da ideia de que todo discurso é imbuído de ideologia (uma "falsa consciência" que expressa o ponto de vista de uma classe social a respeito da realidade), a autora demonstra que os discursos politicos sobre os motivos da inclusão obrigatória da Sociologia na Educação Básica veiculavam a ideologia burguesa para a manutenção da ordem capitalista.

Gesteira evidencia esse fato ao observar que as justificativas para a introdução da Sociologia na Educação Básica, apresentadas nos discursos de representantes de instituições politicas, se baseavam, em geral, na "ideologia do cidadão produtivo". Isso porque os deputados e senadores que defendiam a inclusão da Sociologia como disciplina escolar obrigatória delegavam em seus discursos as seguintes finalidades ao ensino de Sociologia: (1) formar a juventude para o exercício da cidadania e (2) tornar a juventude mais adaptável e flexivel ao mercado de trabalho (GESTEIRA, 2018).

Para os agentes do campo político, por meio da Sociologia, a juventude poderia conhecer a realidade onde está inserida, desenvolver um "senso crítico" e se tornar mais reflexiva, o que permite o desenvolvimento de habilidades como: "o conhecimento e exercício dos direitos e deveres, inserção na vida política e modificação da própria realidade", além de "torná-los mais (...) adaptáveis no contexto da acumulação flexível” (GESTEIRA, 2018, p. 158).

\footnotetext{
9 Gesteira utilizou a dissertação de mestrado de Azevedo para realizar o levantamento das fontes.
} 
Os sentidos do ensino de Sociologia: o que dizem egresso/as da licenciatura em Ciências Sociais da UFSC | Marcelo Cigales, Inaê label Barbosa, Sabrina de Freitas Smialoski e Beatriz Melchioretto Claudino dos Santos

Segundo a autora, essa "ideologia do cidadão produtivo" busca mascarar a divisão de classes da sociedade (ao oferecer uma falsa igualdade aos indivíduos por meio da ideia de cidadania) e atender às necessidades do mercado (garantindo a formação de um tipo de mão de obra adequada às mudanças no sistema produtivo). Assim, os sentidos da Sociologia no Ensino Médio orbitam, principalmente, ao redor das temáticas sobre a cidadania (por meio da reflexão, inserção e intervenção na realidade social) e da adequação ao mundo do trabalho (por meio do desenvolvimento de flexibilidade e adaptabilidade frente a diferentes circunstâncias).

Em síntese, Azevedo (2014) e Gesteira (2018) demonstram que os sentidos pedagógicos atribuídos a Sociologia no Ensino Médio no campo político referem-se, em geral: a) ao desenvolvimento do senso crítico e da reflexividade; b) à formação para a cidadania; c) a "formação humanística"; d) a introdução da juventude ao mercado de trabalho; e, d) a transformação e modificação da realidade social.

\section{Campo acadêmico ${ }^{10}$}

Em relação ao campo acadêmico há um consenso de que o ensino de Sociologia, e a Educação Formal como um todo, deveriam ter por finalidade a formação para a cidadania. A própria LDBEN de 1996 explicita em seu Artigo 36 que os conhecimentos de Filosofia e Sociologia deveriam ser orientados para o desenvolvimento da cidadania, fato que se amplia a partir da Lei 11.684/2008 quando traz o caráter de disciplina e a possibilidade de nortear de forma mais específica sua finalidade na Educação Básica. Cabe lembrar que nos anos 2000, os Parâmetros Curriculares Nacionais do Ensino Médio (PCNEM), baseando-se na LDBEN, buscavam reformular as competências necessárias para o Ensino Médio, sendo que os conceitos de contextualização, interdisciplinaridade e autonomia eram algumas das pautas defendidas para a constituição desse nível de ensino naquele momento.

\footnotetext{
10 Nos referimos ao campo acadêmico por entender que os documentos oficiais, publicados pelo campo político e analisados nessa seção, são produzidos com a colaboração de especialistas, de forma que a visão sobre o sentido pedagógico da Sociologia expresso nesses documentos é produzido por agentes do campo acadêmico.
} 
Os sentidos do ensino de Sociologia: o que dizem egresso/as da licenciatura em Ciências Sociais da UFSC | Marcelo Cigales, Inaê label Barbosa, Sabrina de Freitas Smialoski e Beatriz Melchioretto Claudino dos Santos

Nos PCNEM, ao invés de conhecimentos específicos de Sociologia, são colocados conhecimentos de Ciências Sociais, ou seja, abrangem Sociologia, Antropologia e Ciência Politica. Esse documento aponta dois eixos principais da área: relação indivíduo e sociedade e dinâmica social, que permitiria “(...) instrumentalizar o aluno para que possa decodificar a complexidade da realidade social" (BRASIL, 2000, p. 37), assumindo, assim, uma postura reflexiva e crítica. A relação da área com o exercício da cidadania também é citada no documento, retomando a LDBEN.

Mais tarde, em 2006, com a formulação das Orientações Curriculares Nacionais para o Ensino Médio (OCNEM) será criticado o papel da Sociologia como responsável pela formação para a cidadania, como está presente na LDBEM, pois essa seria a função geral da Educação Formal e não especificamente do ensino de Sociologia. Nesse sentido, as OCNEM se voltaram para a discussão de como as teorias sociológicas poderiam auxiliar a juventude com a aprendizagem de uma linguagem especializada sobre o mundo social.

Para as OCNEM o pensamento sociológico possibilitaria tais impactos a partir de dois papéis centrais: a desnaturalização e o estranhamento. A desnaturalização consiste numa mudança de visão em relação aos argumentos naturalizadores, em que os fenômenos sociais são encarados como uma tendência natural, ou seja, são neutros, inevitáveis e orgânicos. A desnaturalização provocaria uma perda da ingenuidade, de maneira que o indivíduo passaria a enxergar arbitrariedades no percurso dos fenômenos, dito nas palavras das OCNEM: “ (...) certas mudanças ou continuidades históricas decorrem de decisões, e essas, de interesses, ou seja, de razões objetivas e humanas, não sendo fruto de tendências naturais" (BRASIL, 2006, p. 106). O estranhamento não é específico da Sociologia, porém grande é a sua contribuição. Consistiria no processo de problematização de acontecimentos corriqueiros que passam despercebidos. Dessa maneira, os fenômenos passariam a exigir explicação e compreensão que não eram necessárias anteriormente.

Além disso, considera-se que o ambiente escolar, como um todo, forma uma mediação entre o sujeito e o mundo, entre o privado e o público, de 
Os sentidos do ensino de Sociologia: o que dizem egresso/as da licenciatura em Ciências Sociais da UFSC | Marcelo Cigales, Inaê label Barbosa, Sabrina de Freitas Smialoski e Beatriz Melchioretto Claudino dos Santos

maneira que auxilie na formação do indivíduo. Assim sendo, a disciplina de Sociologia deveria traduzir e recortar as teorias científicas, pensando na adequação para a juventude, tendo em vista que o campo científico e escolar promoveriam habitus diferenciados, faz-se então necessário a transição ciência-disciplina. Tal transição poderia ser realizada através de três recortes: conceitos, temas e teorias, de maneira que todos dialoguem para a formação de um conhecimento completo. De acordo com o documento, eles representam dimensões que o ensino de Sociologia no Ensino Médio deveria atender: “(...) uma explicativa ou compreensiva - teorias; uma lingüística ou discursiva - conceitos; e uma empírica ou concreta - temas" (BRASIL, 2006, p.117).

Ainda cabe citar a Base Nacional Comum Curricular (BNCC) criada com o objetivo de unificar um conjunto de competências e conteúdos ao redor de um currículo nacional. A área de Ciências Humanas e Sociais Aplicadas, que contempla as disciplinas de Filosofia, Geografia, História e Sociologia, é caracterizada pelo objetivo de incentivar questionamentos sobre o indivíduo e o mundo, de maneira que o/a estudante adquira uma postura crítica em relação às categorias que regem a sociedade e possa problematizálas. Portanto, a principal habilidade que o/a estudante adquire com a área é a indagação sobre o mundo: "Aprender a indagar, ponto de partida para uma reflexão crítica, é uma das contribuições essenciais das Ciências Humanas e Sociais Aplicadas para a formação dos estudantes do Ensino Médio.” (BRASIL, 2017, p. 549, grifos do documento). Assim sendo, a Base não pontua objetivos específicos para a disciplina de Sociologia, mas sim objetivos dispersos em toda a área de Ciências Humanas e Sociais Aplicadas.

Em sintese, pode-se dizer que não há um consenso quanto ao sentido do ensino de Sociologia nos documentos oficiais. Apenas as OCNEM apontam sentidos específicos para a disciplina, enquanto a LDBEN aborda Filosofia e Sociologia, os PCNEM Ciências Sociais e a BNCC Ciências Humanas e Sociais aplicadas. E quanto aos sentidos, o desenvolvimento da cidadania é vinculada ao ensino da Sociologia na LDBEN e nos PCNEM, enquanto as OCNEM desprezam essa colocação e vinculam à desnaturalização e ao estranhamento do mundo. Tanto a BNCC quanto os PCNEM associam o ensino 
Os sentidos do ensino de Sociologia: o que dizem egresso/as da licenciatura em Ciências Sociais da UFSC | Marcelo Cigales, Inaê label Barbosa, Sabrina de Freitas Smialoski e Beatriz Melchioretto Claudino dos Santos

da Sociologia como garantidor de uma postura critica, reflexiva e questionadora do/a estudante sobre o mundo social. Os PCNEM e as OCNEM também colocam o ensino de Sociologia como proporcionador de instrumentos e linguagem especializada sobre a realidade social. Dessa forma, fica claro que os sentidos são diversos tanto entre os documentos quanto dentro de um mesmo documento.

\section{Campo escolar}

Além do campo político e acadêmico, cabe destacar os sentidos atribuídos ao ensino da Sociologia no campo escolar, no qual destacam-se os trabalhos de Santos (2016) e Rêses (2016) que analisam a visão de professores/as que lecionam a disciplina de Sociologia e de estudantes do Ensino Médio. Enquanto o primeiro investigou os sentidos da Sociologia entre professores/as com e sem formação em Ciências Sociais, o segundo se voltou para compreender a percepção de estudantes concluintes do Ensino Médio.

A pesquisa de Santos (2016), que tem como base de dados entrevistas realizadas por meio de grupos focais com 24 professores/as da rede pública do DF, constatou que a Sociologia é vista como instrumento de conscientização tendo em vista a formação para a cidadania. Essa percepção é uma referência comum no discurso dos/as professores/as, tanto dos/as formados/as em Ciências Sociais, quanto daqueles/as com formação em outras áreas ${ }^{11}$. Entretanto, a análise aponta também que há ideias diferentes quanto ao significado do que seria conscientização, assim como do que seria uma formação para cidadania. Desta forma o autor cria dois eixos de análise. Enquanto o primeiro refere-se à Sociologia "como um meio de formar o cidadão com consciência sociológica", o segundo, diz respeito ao "conhecimento sociológico como meio de formar o cidadão com consciência política" (SANTOS, 2016, p. 45).

O autor ainda ressalta que a aplicabilidade da Sociologia na vida cotidiana é uma preocupação mais presente entre os/as professores/as forma-

11 O discurso similar dos dois grupos acerca do papel da Sociologia como formar um cidadão consciente, segundo o autor se dá em função do contexto histórico de redemocratização do país na época. 
Os sentidos do ensino de Sociologia: o que dizem egresso/as da licenciatura em Ciências Sociais da UFSC | Marcelo Cigales, Inaê label Barbosa, Sabrina de Freitas Smialoski e Beatriz Melchioretto Claudino dos Santos

dos/as em outras áreas que não as Ciências Sociais. Analisa também a diferenciação grupal, visto que, variáveis como tipo de formação do/a professor/a e local de trabalho influenciam na forma como estes enxergam a disciplina de Sociologia. Após análise dos dados, constata que em um extremo encontram-se professores/as com formação em Ciências Sociais e que trabalham no Plano Piloto/Arredores no DF, já no outro extremo encontram-se professores/as com formação em outras áreas e que trabalham em cidades satélites.

Embora ambos os grupos procuram situar o/a educando/a em suas condicionantes sociais, como um agente, um cidadão consciente, há uma diferenciação em suas finalidades. Para os/as professores/as formados/as em Ciências Sociais a ampliação de conhecimento sobre a sociedade que a Sociologia fornece não está vinculada a uma prática social, no sentido de algum projeto de sociedade ou reforma social. Na perspectiva destes/as professores/as a aquisição de tais conhecimentos e instrumentos sociológicos possibilita ao e à estudante fazer opções em sua vida social. Ou seja, a Sociologia serviria como uma ferramenta para os alunos compreenderem as relações sociais. "Um instrumento de descoberta do educando enquanto agente social, capaz de fazer opções. Inclusive um agente capaz de fazer a opção de agir ou não no sentido de transformar a realidade social" (SANTOS, 2016, p. $66)$.

Já para os/as professores/as formados/as em outras áreas, em contraponto, essa tomada de consciência implica em mudanças na vida do/a estudante. Neste caso, o conhecimento sociológico instrumentaliza o/a estudante para que possa resolver problemas e conflitos nas suas relações cotidianas. O processo de conscientização do/a estudante tem como finalidade uma ação politica no sentido de resolver problemas sociais. Desta forma, o autor destaca que este grupo se preocupa mais com as "potencialidades pragmáticas" da Sociologia, e isso se reflete até mesmo nos aspectos de preparação para vestibulares e exames, mesmo que de forma indireta, pois, para este grupo, a disciplina serve também para desenvolver habilidades exigidas em tais exames, como interpretação e produção de textos. 
Os sentidos do ensino de Sociologia: o que dizem egresso/as da licenciatura em Ciências Sociais da UFSC | Marcelo Cigales, Inaê label Barbosa, Sabrina de Freitas Smialoski e Beatriz Melchioretto Claudino dos Santos

Confrontando os dois grupos, Santos (2016) afirma que os/as professores/as formados/as em Ciências Sociais têm uma concepção de Sociologia como sendo uma ciência pronta e consolidada, diferente da posição dos/as professores/as formados/as em outras áreas que falam sobre uma Sociologia em movimento, em transformação, reflexiva, que precisa ser contextualizada. Segundo o autor, embora o primeiro grupo reconheça também a Sociologia enquanto uma ciência não estável e contextual, este teme a uma abordagem baseada no espontaneísmo e senso comum, o que resultaria em perda de certa autoridade ou de um status de especialista. Para Santos essa afirmação da importância de um conhecimento científico, que torna os conceitos sociológicos como elementos centrais, se dá em função de uma afirmação de identidade destes sujeitos, como portadores destes conhecimentos, como especialistas, como sociólogos/as.

Conclui-se então que os/as licenciados/as em Ciências Sociais, identificam-se primordialmente como especialistas nesta área do conhecimento e não como docentes, ou seja, a condição de sociólogo/a antecede a condição de professor/a. Este fato, segundo os autores do livro, se dá em função de um processo de formação acadêmica, no qual, de modo geral, os e as estudantes cursam as disciplinas da Sociologia, da Antropologia e da Ciência Politica, nos semestres iniciais enquanto as disciplinas pedagógicas somente são cursadas nos semestres posteriores. Tal processo indica que a formação pedagógica do/a professor/a de Sociologia encontra-se subordinada a formação disciplinar (RÊSES; SANTOS; RODRIGUES, 2016, p. 197-198).

Quanto à representação de alunos/as acerca da disciplina de Sociologia, Rêses (2016) apresenta uma pesquisa que tem como base de dados, entrevistas realizadas por meio de grupos focais com 79 adolescentes com idades entre 16 e 20 anos do terceiro ano do Ensino Médio da rede pública do DF. Segundo o autor, a escolha pelo terceiro ano aconteceu de forma proposital, pois desta forma, por ter contato com a Sociologia desde o primeiro ano, o/a aluno/a já acumulou um certo grau de aprendizagem acerca da disciplina, o que é uma condição necessária para se constituir como objeto de representação social. 
Os sentidos do ensino de Sociologia: o que dizem egresso/as da licenciatura em Ciências Sociais da UFSC | Marcelo Cigales, Inaê label Barbosa, Sabrina de Freitas Smialoski e Beatriz Melchioretto Claudino dos Santos

Outra característica de caráter intencional na escolha dos/as informantes foi uma segmentação dos grupos: metade com alunos/as moradores/as do assentamento de Santa Maria, região periférica com famílias de baixa renda em lotes semi urbanizados, e metade com alunos/as moradores/as da Asa Norte, região da área central de Brasília, conhecida como Plano Piloto, dotada de melhor infraestrutura e famílias com maior renda e escolaridade. A variável "local de moradia" assume, desta forma, uma posição central nessa pesquisa.

Rêses (2016) percebe, em suas análises, similaridades e diferenças entre os/as estudantes dos dois grupos. Segundo o autor, em ambos os grupos há uma valorização dos/as alunos/as acerca da disciplina no que concerne ao entendimento maior sobre a sociedade, as instituições e os grupos sociais, à formação do senso crítico e cidadania. Identifica-se que os/as alunos/as também valorizam a disciplina enquanto conteúdo de Ensino Médio, a colocando no mesmo patamar de outras disciplinas. Essa valorização ultrapassa algumas dificuldades da disciplina como sua ausência de forma direta em exames e vestibulares e suas oscilações de presença no ensino básico. Para os/as alunos/as a sua importância parte de outras ordens, como para a conscientização política e social.

Entre os dois grupos há, porém, uma diferença quanto às finalidades da disciplina. Os/as alunos/as da região periférica (Santa Maria) expressam que a formação em Sociologia estaria baseada numa orientação pragmática e técnica, em que a atuação dos cidadãos por demandas sociais estariam voltadas, principalmente, para o nivel local e diretamente associadas à melhoria da qualidade de vida do local onde vivem. Desta forma, a Sociologia, para estes/as alunos/as, assume o papel de aplicabilidade na realidade social, de forma intervencionista. Já para os/ alunos/as da região central (Asa Norte), a discussão gira mais em torno do contexto escolar e da preocupação com o ingresso no Ensino Superior. Segundo Rêses, os/as alunos/as deste grupo também apresentam uma concepção pragmática da Sociologia, porém esta se relaciona mais a uma ascensão escolar. Para ele, um fator determinante que explica essa situação encontra-se no capital cultural proveniente da fa- 
Os sentidos do ensino de Sociologia: o que dizem egresso/as da licenciatura em Ciências Sociais da UFSC | Marcelo Cigales, Inaê label Barbosa, Sabrina de Freitas Smialoski e Beatriz Melchioretto Claudino dos Santos

mília desses/as alunos/as, visto que a região central possui um índice de escolaridade muito maior entre os/as moradores/as do que a região periférica.

Rêses (2016) conclui que os/as alunos/as de Ensino Médio da rede pública do Distrito Federal possuem uma percepção acerca da disciplina de Sociologia bastante similar às das orientações e postulados dispostos nos documentos oficiais das mudanças no Ensino Médio, onde o papel principal do ensino da Sociologia é a formação para o exercício da cidadania. Desta forma, os dois grupos de alunos/as concordaram com essa perspectiva de formação, porém sob dois pontos de vista diferentes. Enquanto o grupo da região periférica, tem um olhar voltado na melhoria das condições de vida, o outro, da região central, tem um olhar que visa a progressão escolar. Portanto, ambos os grupos valorizam o ensino de Sociologia em sua formação pessoal, porém suas finalidades divergem em função dos distintos contextos sociais.

\section{Síntese}

Uma primeira observação que se pode fazer a partir da leitura desses trabalhos é que, por um lado, o discurso da cidadania está presente de forma direta ou indiretamente no papel que o ensino da Sociologia poderia representar na educação brasileira. Por outro lado, se observa que quanto mais a discussão se aproxima do campo acadêmico (especializado) das Ciências Sociais mais essa concepção é relativizada, pois não seria uma tarefa específica do ensino da Sociologia "formar para a cidadania" mas sim de toda a educação brasileira ${ }^{12}$. O que se discutirá a partir de então é a possibilidade da Sociologia tornar a cidadania como tema de pesquisa e também de capacitar os/as estudantes dessa disciplina a se tornarem sujeitos críticos e participantes dos processos sociais.

Uma segunda questão volta-se para a concepção de que a Sociologia seria uma disciplina crítica. Porém, esse sentido torna-se mais discutido e

12 É importante salientar que outras áreas, como a Filosofia também critica essa postura da LDBEM sobre formar para a cidadania. Ver mais em Silvio Gallo (2016). 
Os sentidos do ensino de Sociologia: o que dizem egresso/as da licenciatura em Ciências Sociais da UFSC | Marcelo Cigales, Inaê label Barbosa, Sabrina de Freitas Smialoski e Beatriz Melchioretto Claudino dos Santos

problematizado quanto mais se aproxima do campo acadêmico, visto que não se tem um consenso de que a criticidade seria voltada para compreender e analisar a realidade social ou com o intuito de buscar transformá-la a partir do engajamento em ações e movimentos sociais. Esse tópico também é discutido por Santos (2016) e Rêses (2016) ao analisarem como essas representações - da criticidade científica e engajada - se atrelam a diversas variáveis, tais como: a formação dos/as professores/as e da origem social dos/as estudantes do Ensino Médio.

A partir dessa discussão, podemos nos perguntar sobre o impacto desses sentidos na concepção do professorado formado na UFSC. Há um consenso no discurso desses/as professores/as? Quais os sentidos mais recorrentes na concepção desse público? Os sentidos fazem referência aos apresentados pelos discursos legislativos, pelos documentos curriculares oficiais e/ou pelos/as professores/as e estudantes da Educação Básica? Eis algumas questões que serão tratadas a seguir, a partir da análise das entrevistas.

\section{O que pensam os professores formados na UFSC?}

Nesta seção apresentamos os dados da pesquisa sobre os sentidos pedagógicos da Sociologia a partir da visão dos/as professores/as formados/as na UFSC. Destacamos que no roteiro da entrevista havia um bloco destinado a compreender a visão dos/as entrevistados/as sobre o papel da Sociologia na Educação Básica, bem como das percepções sobre as correntes teóricas que se identificavam para lecionar a Sociologia. Mais detalhadamente, o bloco de questões centrava-se nas seguintes perguntas: a) Qual era a representação sobre a profissão do/a professor/a de Sociologia, e do ensino de Sociologia antes de entrar no curso?, b) Após sua formação, sua percepção mudou?; c) Na sua opinião para que serve o ensino de Sociologia hoje? d) Na sua prática docente, você se identifica com alguma perspectiva teórica para lecionar Sociologia? Se sim, a quem você atribui essa influência (da formação do curso de C.S, de leituras complementares, de formação complementar, da socialização no ambiente escolar, de Revistas de Ensino, etc.)? 
Os sentidos do ensino de Sociologia: o que dizem egresso/as da licenciatura em Ciências Sociais da UFSC | Marcelo Cigales, Inaê label Barbosa, Sabrina de Freitas Smialoski e Beatriz Melchioretto Claudino dos Santos

Com o objetivo de organizar a descrição e análise dos dados, criamos uma tabela com os dados dos/as entrevistados/as com o objetivo de conhecer seus perfis, assim como os principais sentidos atribuídos ao ensino de Sociologia. Sobre o perfil do público analisado, podemos aferir que possuem entre 31 e 57 anos, são a primeira geração da família a cursar o ensino superior, a maioria cursou a Educação Básica em escolas públicas e privadas e possuem formação na pós-graduação seja no mestrado e alguns casos no doutorado. Isso nos possibilita pensar a ampliação ao acesso das camadas populares ao ensino superior no Brasil, visto as trajetórias desses agentes são marcadas pelo acesso ao capital cultural institucionalizado em forma de títulos escolares, o que os distancia de sua geração passada, visto que a maioria seguiu estudando em nivel de pós-graduação, sendo alguns casos migrado para outros cursos como Medicina e Pedagogia, como podemos analisar no quadro 01, abaixo representado.

Mais especificamente, sobre os sentidos atribuidos ao ensino da Sociologia, podemos destacar três categorias, baseado na frequência em que apareceram na fala dos/as entrevistados/as: a) Formar sujeitos críticos e conscientes do mundo em que vivem, presente em oito entrevistas; b) Afirmar a Sociologia enquanto ciência e fornecedora de ferramentas analíticas, presente em cinco entrevistas; e, c) Promover a transformação social e a militância, presente em três entrevistas. Essas categorias não sintetizam a amplitude das respostas, mas nos ajudam a visualizar as principais representações do ensino da Sociologia atribuídos por esse público. 
Os sentidos do ensino de Sociologia: o que dizem egresso/as da licenciatura em Ciências Sociais da UFSC | Marcelo Cigales, Inaê label Barbosa, Sabrina de Freitas Smialoski e Beatriz Melchioretto Claudino dos Santos

\begin{tabular}{|c|c|c|c|c|c|}
\hline Pseudônimo & Idade & $\begin{array}{l}\text { Escolaridade/ocupa- } \\
\text { ção dos pais }\end{array}$ & $\begin{array}{l}\text { Estudou em } \\
\text { escola pública } \\
\text { ou privada? }\end{array}$ & $\begin{array}{l}\text { Formação } \\
\text { depois da li- } \\
\text { cenciatura }\end{array}$ & $\begin{array}{l}\text { Sentido do ensino de } \\
\text { Sociologia }\end{array}$ \\
\hline Alessandra & 57 & $\begin{array}{l}\text { Sem informação so- } \\
\text { bre o pai. Mãe com } \\
\text { ensino fundamental } \\
\text { incompleto. }\end{array}$ & $\begin{array}{l}\text { Escola confes- } \\
\text { sional }\end{array}$ & $\begin{array}{l}\text { Participou do } \\
\text { mestrado. }\end{array}$ & $\begin{array}{l}\text { "Trazer luz", análise } \\
\text { critica e romper com a } \\
\text { limitação de pensa- } \\
\text { mento. }\end{array}$ \\
\hline Carlos & 31 & $\begin{array}{l}\text { Pai com ensino fun- } \\
\text { damental completo e } \\
\text { mäe com ensino mé- } \\
\text { dio completo. }\end{array}$ & $\begin{array}{l}\text { Estudou em } \\
\text { escolas públi- } \\
\text { cas e privadas. }\end{array}$ & $\begin{array}{l}\text { Não possui } \\
\text { formação, mas } \\
\text { pretende. }\end{array}$ & $\begin{array}{l}\text { Afirmação da Sociolo- } \\
\text { gia enquanto ciência } \\
\text { mas também voltada à } \\
\text { transformação social. }\end{array}$ \\
\hline Luisa & 32 & $\begin{array}{l}\text { Primeira geração da } \\
\text { familia a cursar ensi- } \\
\text { no superior; } \\
\text { Pai é balconista em } \\
\text { uma farmácia c a mãe } \\
\text { ć costureira. }\end{array}$ & $\begin{array}{l}\text { Ensino básico } \\
\text { público e pri- } \\
\text { vado com bol- } \\
\text { sa. Fez cursi- } \\
\text { nho pré-vesti- } \\
\text { bular. }\end{array}$ & $\begin{array}{l}\text { Mestrado cm } \\
\text { Antropologia. }\end{array}$ & $\begin{array}{l}\text { Promove o diálogo e } \\
\text { situa o individuo no } \\
\text { mundo. }\end{array}$ \\
\hline Roberta & - & $\begin{array}{l}\text { Mãe com ensino fun- } \\
\text { damental incompleto; }\end{array}$ & $\begin{array}{l}\text { Ensino funda- } \\
\text { mental e médio } \\
\mathrm{cm} \text { escola pú- } \\
\text { blica. }\end{array}$ & $\begin{array}{l}\text { Mestrado do } \\
\text { PROFSOCIO; }\end{array}$ & $\begin{array}{l}\text { Desnaturalização e } \\
\text { estranhamento; } \\
\text { Ferramentar os jovens } \\
\text { para entender o mundo } \\
\text { c mudar a realidade. }\end{array}$ \\
\hline Tiago & 32 & $\begin{array}{l}\text { Pai sc aposentou } \\
\text { como eletricista c } \\
\text { mäe dona de casa. } \\
\text { Ambos com Ensino } \\
\text { Fundamental comple- } \\
\text { to. }\end{array}$ & $\begin{array}{l}\text { Ensino básico } \\
\mathrm{cm} \text { escolas par- } \\
\text { ticulares. }\end{array}$ & $\begin{array}{l}\text { Professor esta- } \\
\text { dual desde } \\
2014 \text { e con- } \\
\text { cluiu uma es- } \\
\text { pecialização } \\
\text { em gestão es- } \\
\text { colar para po- } \\
\text { der ter uma } \\
\text { progressão na } \\
\text { carreira. }\end{array}$ & $\begin{array}{l}\text { Expandir a mente do } \\
\text { individuo, fazendo-o } \\
\text { enxergar e ter consci- } \\
\text { ência do mundo, para } \\
\text { poder atuar e lutar. } \\
\text { "Chocar e impressio- } \\
\text { nar". }\end{array}$ \\
\hline Marlon & 39 & $\begin{array}{l}\text { Pai comerciante e a } \\
\text { mäe trabalhava no } \\
\text { cartório. Ambos com } \\
\text { o Ensino Médio } \\
\text { completo, sem curso } \\
\text { superior. } \\
\text { Todos os irmãos com } \\
\text { curso superior. }\end{array}$ & $\begin{array}{l}\text { Ensino básico } \\
\mathrm{cm} \text { escola par- } \\
\text { ticular religio- } \\
\text { sa. }\end{array}$ & $\begin{array}{l}\text { Mestrado na } \\
\text { UFLA pelo } \\
\text { programa de } \\
\text { Administraçāo } \\
\text { - "Ecologia } \\
\text { Aplicada". } \\
\text { Atualmente } \\
\text { está na UFLA } \\
\text { no doutorado } \\
\text { na área de An- } \\
\text { tropologia }\end{array}$ & $\begin{array}{l}\text { "A sociologia não cura } \\
\text { os males do mundo, } \\
\text { mas ela ajuda a dar } \\
\text { mais jogo de cintura". } \\
\text { A imaginação socioló- } \\
\text { gica (Wright Mills) é } \\
\text { citada como uma fer- } \\
\text { ramenta da sociologia } \\
\text { que "ajuda a entender } \\
\text { as situaçōes econômi- } \\
\text { cas, políticas, etc". }\end{array}$ \\
\hline Paola & 39 & $\begin{array}{l}\text { Pais Ensino Funda- } \\
\text { mental incompleto. } \\
\text { Pai agricultor, mãe } \\
\text { opcrária }\end{array}$ & $\begin{array}{l}\text { Toda a trajetó- } \\
\text { ria cm escola } \\
\text { pública }\end{array}$ & $\begin{array}{l}\text { Doutorado cm } \\
\text { Educaçāo USP, } \\
\text { graduanda cm } \\
\text { Pedagogia }\end{array}$ & $\begin{array}{l}\text { Ampliar o campo de } \\
\text { reflexão, questionar e } \\
\text { ver outras possibilida- } \\
\text { des a partir da teoria. }\end{array}$ \\
\hline Rachel & 32 & $\begin{array}{l}\text { Pais Ensino Funda- } \\
\text { mental incompleto. } \\
\text { Relojoaria. }\end{array}$ & $\begin{array}{l}\text { Escola pública' } \\
\text { privada. Pri- } \\
\text { meira geração a } \\
\text { cursar Ensino } \\
\text { Superior }\end{array}$ & $\begin{array}{l}\text { Mestrado cm } \\
\text { Antropologia, } \\
\text { cursando gra- } \\
\text { duação } \mathrm{cm} \\
\text { Medicina }\end{array}$ & $\begin{array}{l}\text { Sair do conformismo e } \\
\text { compreender o mundo } \\
\text { para viver melhor em } \\
\text { sociedade. }\end{array}$ \\
\hline
\end{tabular}

Fonte: Elaboração dos/as pesquisadores/as 
Os sentidos do ensino de Sociologia: o que dizem egresso/as da licenciatura em Ciências Sociais da UFSC | Marcelo Cigales, Inaê label Barbosa, Sabrina de Freitas Smialoski e Beatriz Melchioretto Claudino dos Santos

Quadro 01: Perfil dos entrevistados e os sentidos da Sociologia

A primeira consideração que se pode fazer a partir desses dados é a ausência dos discursos mais presente no campo politico sobre a formação para a cidadania, visto que a ênfase na fala dos/as entrevistados/as está mais voltado a pensar a Sociologia como um conhecimento critico e científico, elementos que caracterizam os sentidos da Sociologia junto ao campo acadêmico. Isso pode ser um efeito da trajetória mais duradoura desses agentes no espaço social acadêmico já que a grande maioria deles possui uma vida carreira prolongada em nível de pós-graduação, o que pode ter efeito junto a construção desse sentido. Outra característica também se destaca, visto que parte considerável do público entrevistado optou por continuar os estudos em nível de pós-graduação ou migrar para outros cursos, o que pode ser reflexo das condições precárias do trabalho docente, que faz com que, por exemplo, no Estado de Santa Catarina, mais da metade do professorado da rede pública de ensino tenham contrato temporário de trabalho (KATREIN, MARCASSA, 2017).

Passamos para a análise das categorias:

a) Formar sujeitos críticos e conscientes do mundo em que vivem: esta é a categoria mais presente na fala dos/as entrevistados/as. Segundo eles/as, o papel da Sociologia é desenvolver uma consciência crítica sobre os diversos problemas em que a sociedade enfrenta na atualidade, como a desigualdade social, a violência, o autoritarismo, o papel da democracia, etc.

É muita coisa, acho que vou sintetizar. É pra gente não achar que as coisas estão dadas, pra gente sair desse conformismo, pra gente compreender o mundo, compreender o quanto a gente pode ser manipulado, o quanto a gente pode manipular. Entender a nossa relação com o outro, com outras formas de conhecimento. Entender do que é feito da nossa vida, do que a gente pode fazer, entender porque se tem violência, entender porque o governo anda mal, porque que a questão é a corrupção. A gente está num momento que está surgindo tanta coisa, tanta palavra importante sem significado né. O quanto as pessoas não compreendem, todo mundo de forma geral. Tá distante de compreender o mundo [...]. Não só a questão de política, mas a questão dos hábitos, de se colocar no mundo, parece que está todo mundo com uma venda. E porque que incomoda alguém, se um 
Os sentidos do ensino de Sociologia: o que dizem egresso/as da licenciatura em Ciências Sociais da UFSC | Marcelo Cigales, Inaê label Barbosa, Sabrina de Freitas Smialoski e Beatriz Melchioretto Claudino dos Santos

menino quer beijar o outro? Porque que me incomoda se a mulher quer tirar o bebê, sabe. Porque que as pessoas se incomodam com essas coisas? Acho que a sociologia joga isso pra gente, bom me incomoda por conta disso, deixa eu ver se eu me explico. É pra gente viver melhor em sociedade no final das conta, pra gente entender mais o que é democracia, o que que implica em mim viver num estado democrático, que parte eu tenho nisso e o que eu possa fazer para viver melhor frente ao outro né, pra comer melhor, para ter um trabalho melhor, para entender as coisas. Eu tô num curso agora cara que esses dias, a galera falou que a democracia é o voto da maioria, sabe? Essa é a ideia que se tem, que a democracia é o voto da maioria, e se $51 \%$ decidir que sim então essa é a democracia. Eu tenho vontade de bater com a cabeça na parede quando escuto essas coisas, sabe qual que é a questão? Faltou sociologia no Ensino Médio, entende? Porque a galera sabe fazer equação de segundo grau, que não serve pra nada, e não sabe o que é democracia num momento em que a gente precisa saber o que é democracia! Então tinha que tirar as aulas de matemática ou diminuir a carga horária, ensinar o que é preciso, e ensinar o que é esse mundo que a gente vive. E como a gente deve viver nesse mundo que a gente vive e como a gente deve fazer para tornar ele ainda melhor, entender que se as pessoas vivem melhor eu vivo melhor também né, se a desigualdade social diminuir eu vou viver melhor também, vai ser bom pra mim também. É tanta coisa cara, tanta coisa que pode ser ensinada na sociologia, antropologia junta que é fundamentalmente pra gente viver melhor em sociedade, e compreender melhor a sociedade que a gente vive, e não ficar com esses absurdos né, meu deus, eu tenho vontade de dizer assim: "olha vai estudar!" deixa um pouco a Medicina e estuda uma tarde, vai escutar um vídeo da Marilena Chauí, ou alguma coisa pra você entender o que você está falando. (Rachel, 32 anos, concluiu a licenciatura em 2010).

Sem sociologia, nossa... história é incrivel porque ela te mostra o que o mundo já viveu, né? E a sociologia, eu acho que ela consegue fazer o gancho entre o que se viveu e o que está se vivendo. [...] E eu acho que é por aí. Sacar e botar o aluno no mundo. Você está aqui, ó, por $\mathrm{A}, \mathrm{B}$ e $\mathrm{C}$ motivos. E que você é filho de imigrantes, você está na classe trabalhadora porque parte da tua familia era escravizada. Você é um cerne de uma cebola ali, sabe? Um monte de camada, um monte de coisa acontecendo e você está aqui agora. E pra mim é isso, tu te situa a partir daí. (Luísa, 32 anos)

Se a gente conseguir fazer, dentro da escola, com que os jovens só se enxerguem, se enxerguem quanto a sujeito histórico, dentro do seu processo, dentro do seu contexto, a gente já avançou grandes passos assim. Eu acho que a sociologia serve pra gente não sofrer... Pra gente ensinar os jovens a não sofrer de sindrome de Poliana, e pra não desistir de tudo assim (risos). (...) Então eu acho que ela tem essa potência de jogar os jovens no lugar onde eles não se enxergavam, inclusive. (Roberta, concluiu a licenciatura em 2016)

\section{b) Afirmar a Sociologia enquanto ciência e fornecedora de ferra-} mentas analiticas: a segunda categoria mais presente na fala dos/as entrevistados/as, que afirmam que a Sociologia é uma ciência que proporciona 
Os sentidos do ensino de Sociologia: o que dizem egresso/as da licenciatura em Ciências Sociais da UFSC | Marcelo Cigales, Inaê label Barbosa, Sabrina de Freitas Smialoski e Beatriz Melchioretto Claudino dos Santos

teorias e conceitos para os individuos desvendar a complexidade do mundo social.

Da experiência que eu tive assim, a sociologia serviu pra ferramentar esses jovens [...] Diante da sociologia a gente fala bem assim olha: "o mundo funciona desse jeito, existem algumas capacidades que a gente pode exercer nesse processo, essas são as suas grandes teorias, as suas grandes bases, mas a maneira de subverter", para além de ser revolucionário tá gente? (Roberta, concluiu a licenciatura em 2016)

Olha... Eu falava pra minha sala, a sociologia ela não... Cura os males do mundo, mas ela ajuda a dar mais jogo de cintura, ela amplia a imaginação né, uma metáfora utilizada muito pelo Wright Mills a da Imaginação Sociológica, é um texto que eu utilizo, da mesma forma que o pedreiro utiliza a pá do pedreiro, a ferramenta do pedreiro né, da mesma forma que a ferramenta de um médico - o estetoscópio sabe, eu relaciono, eu digo que a ferramenta do sociólogo e para o estudante de sociologia é a imaginação, a Imaginação Sociológica, a imaginação que é pra gente entender as situações econômicas, políticas e tal, a gente tem que conseguir imaginar e a sociologia ajuda nisso (...) (Marlon, 39 anos, concluiu a licenciatura em 2009).

c) Promover a transformação social e a militância: é a terceira categoria mais presente na fala dos/as entrevistados/as e de maneira geral vem no sentido de que os problemas sociais devem ser compreendidos para serem transformados. A Sociologia teria esse papel de transformação da realidade social, a partir do momento em que se elucidam as questões, os problemas sociais, os indivíduos teriam maior condição de modificá-los.

A minha ideia era chegar com eles e fazer o debate da ciência, da ciência social, trazer os conceitos, as teorias... uma coisa que a [professora] sempre batia e eu peguei dela, com rigor, né, com rigor metodológico... assim né, pelo PIBID... me ter feito a crítica, né, como a Sociologia é representada, como há um diálogo contemporâneo... ah, vamos falar de bullying, a Sociologia fala, então... eu tinha crítica a este tipo de visão. Então este tipo de aula, este tipo de representação da Sociologia no Ensino Médio eu queria e quero superar, mostrar que a Sociologia é uma ciência, que tem vários olhares sobre os fenômenos sociais e deixar que a galera pense com a sua cabeça. Mas, de entender que a Sociologia ela não é homogênea, que ela tem várias respostas pra mesma pergunta. Então de transmitir este aspecto enquanto ciência mesmo de instrumentalizar... pegando muita influência na leitura do "Escola e democracia" do Saviani, na questão de instrumentalizar estes jovens na questão do capital escolar mesmo, de fazer eles lerem, de fazer o povo escrever, se apropriar dessas linguagens, que é através dessas linguagens que você tem mobilidade social, você ingressa numa universidade, num concurso, num ensino técnico. Então fazer esta questão da Sociologia como uma Ciência e também da militância em vários temas, né. A questão do combate ao racismo, combate ao machismo, esta questão está muito presente na ideia de uma Sociologia na escola, de uma militância, da crítica ao capitalismo, nisso de ter um posicionamento mesmo, perante a desigualdade social. [...] então é... combater, enfrentar assim, militar nessas duas linhas. Mas também na 
Os sentidos do ensino de Sociologia: o que dizem egresso/as da licenciatura em Ciências Sociais da UFSC | Marcelo Cigales, Inaê label Barbosa, Sabrina de Freitas Smialoski e Beatriz Melchioretto Claudino dos Santos

\begin{abstract}
questão do rigor da ciência que... transmitir pra jovens e pros meus colegas que... pros professores que não entendem que a Sociologia na Escola.... acham que a Sociologia tem que falar sobre... ah tem algum problema de desavença... o povo tem um olhar sobre a sociologia que é isso, debates contemporâneos, né, e combater esta visão também. Mas também se apropriar dos espaços que de certa maneira esse senso comum cria na escola. Estas campanhas maiores. E daí nisso trazer um olhar sociológico, estatístico. (Carlos, 31, formado em 2014).
\end{abstract}

Como se pode ver, algumas falas contém mais de um sentido, mas para efeito de análise é relevante destacar que essas três categorias, em nossa compreensão, elucidam o que os/as professores/as entrevistados/as pensam a respeito do sentido do ensino de Sociologia. Assim, poderíamos dizer que tal sentido vai ao encontro de pensar a Sociologia como uma ciência que possui referencial teórico e metodológico capaz de analisar os fenômenos sociais e tirar conclusões a respeito deles. Essa ciência quando transposta para o nivel escolar, pode levar os/as estudantes a evidenciarem suas posições sociais no mundo, tornando-os mais conscientes e críticos/as a respeito da dinâmica social em que suas vidas estão engendradas. E por fim, dependendo da posição desses sujeitos a Sociologia pode ser uma ferramenta que auxilia na transformação do mundo, ao revelar os mecanismos de poder de determinados sujeitos e instituições em relação à outros.

\title{
Considerações finais
}

Ainda que breve, este artigo buscou contribuir com os estudos que têm como foco o ensino de Sociologia no Brasil. Partindo de uma discussão sobre os sentidos pedagógicos da Sociologia nos diferentes campos (político, acadêmico e escolar), elucidamos que há uma demanda atrelada à disciplina que a coloca como importante ferramenta para a formação da cidadania. Por outro lado, quando mais se adentra no campo acadêmico esse sentido se transforma, acrescentando a sua capacidade crítica e explicativa do mundo social. Na fala dos/as entrevistados/as destacaram-se, portanto, três aspectos que se relacionam com o campo acadêmico: formar sujeitos críticos e reflexivos, afirmando a Sociologia enquanto ciência, promovendo a transformação social e a militância em prol de determinadas demandas atreladas 
Os sentidos do ensino de Sociologia: o que dizem egresso/as da licenciatura em Ciências Sociais da UFSC | Marcelo Cigales, Inaê label Barbosa, Sabrina de Freitas Smialoski e Beatriz Melchioretto Claudino dos Santos

aos movimentos sociais, tal como: o combate ao racismo, ao machismo e a exploração do trabalho pelo capitalismo, etc.

Destaca-se que a representação social dos agentes entrevistados se relaciona diretamente com o campo acadêmico, ainda que em diferentes níveis, possivelmente, atrelado às experiências e trajetórias sociais desses agentes, que possuem uma inserção mais aprofundada no campo, com a realização da pós-graduação e, em alguns casos, da realização de outros cursos de graduação como Medicina e Pedagogia. Assim, será interessante em pesquisas futuras, investigar mais detalhadamente como a trajetória desses agentes se relacionam ao sentido atribuído a Sociologia, já que mesmo sendo todos formados na área e com experiências pedagógicas, os sentidos não são tão homogêneos, mas antes estão relacionados as suas origens e trajetórias sociais.

Também podemos considerar que esta pesquisa reflete um movimento de avaliação do campo de formação de professores, seu objetivo também foi servir de base para futuras reflexões sobre as trajetórias dos egressos do curso de Ciências Sociais, neste caso, com ênfase para os professores de Sociologia. Ao colocarmos evidencia na relação entre os "sentidos pedagógicos"13 do ensino de Sociologia nos campos mais amplos (politico, acadêmico e escolar a partir da revisão da literatura) com o que os dados nos apresentam (pesquisa empírica a partir das entrevistas com egressos da licenciatura), confirmamos que não há uma única linha que direcione os objetivos de ensinar e aprender sociologia, mas antes esses sentidos se relacionam com questões mais amplas, tais como: a pluralidade de paradigmas nas ciências humanas que possuem uma lógica de acúmulo de conhecimentos, ampliando e diversificando o debate sobre a compreensão do mundo social; aos diferentes discursos e representações que o ensino de Sociologia é atrelado, desde uma cidadania-crítica-reflexiva até uma instrumentalização cidadã para o mundo do trabalho, etc.; e por fim, aos diversos sentidos atribuídos ao ensino de Sociologia construídos nos diferentes campos sociais (político, acadê-

\footnotetext{
13 Sobre os sentidos pedagógicos ver o trabalho de Cigales, Franke e Dallmann (2019).
} 
Os sentidos do ensino de Sociologia: o que dizem egresso/as da licenciatura em Ciências Sociais da UFSC | Marcelo Cigales, Inaê label Barbosa, Sabrina de Freitas Smialoski e Beatriz Melchioretto Claudino dos Santos

mico e escolar) que reunidos constituem o campo educacional. Portanto, pôr em evidencia esses discursos e representações, nos auxilia a pensar as funções do ensino de Sociologia na escola básica brasileira, bem como, na tarefa de refletir sobre um currículo formativo para a licenciatura mais diversificado, reflexivo e que busque valorizar as trajetórias sociais dos licenciando como elementos relevantes nesse processo.

\section{Referências}

AZEVEDO, Gustavo Cravo de. Sociologia no ensino médio: uma trajetória político-institucional (1982-2008). Dissertação (Mestrado em Ciência Política). Instituto de Ciências Humanas e Filosofia da Universidade Federal Fluminense, Rio de Janeiro, 2014.

BODART, Cristiano; TAVARES, Caio. A produção sobre o ensino de sociologia escolar nos periódicos brasileiros on-line de estratos superiores, 19962017. In: MAÇAIRA, Julia; FRAGA, Alexandre (Orgs.). Saberes e práticas do ensino de sociologia. Rio de Janeiro: Autografia, 2018, p. 27-56.

BODART, Cristiano das Neves.; SILVA, Roniel Sampaio. Um Raio-X do professor de Sociologia brasileiro: condições e percepções. Estudos de Sociologia (UFPE), v. 2, p. 197-233, 2017.

BODART, Cristiano. Prática de ensino de sociologia: as dificuldades dos professores alagoanos. Mediações-Revista de Ciências Sociais, v. 23, n. 2, p. 455-491, 2018.

BOURDIEU, Pierre. Razões práticas: sobre a teoria da ação. Tradução Mariza Corrêa. Campinas, São Paulo: Papirus, 1996.

BOURDIEU, Pierre. O senso prático. Petrópolis: Vozes, 2009.

BOURDIEU, Pierre. Notas provisórias sobre a percepção social do corpo. Revista Pró-posições. v. 25, n.1. p. 247-256, 2014.

BRASIL. Lei $\mathrm{n}^{\circ}$ 9.394, de 20 de dezembro de 1996. Estabelece as diretrizes e bases da educação nacional. Diário Oficial da União, Brasília, 23 de dezembro de 1996.

BRASIL. Parâmetros Curriculares Nacionais do Ensino Médio. Parte IV Ciências Humanas e suas Tecnologias. Ministério da Educação: Brasília, 2000.

BRASIL. Orientações Curriculares para o Ensino Médio. Ministério da Educação: Brasília, 2006. 
Os sentidos do ensino de Sociologia: o que dizem egresso/as da licenciatura em Ciências Sociais da UFSC | Marcelo Cigales, Inaê label Barbosa, Sabrina de Freitas Smialoski e Beatriz Melchioretto Claudino dos Santos

BRASIL. Base Nacional Comum Curricular. Ministério da Educação: Brasília, 2017.

BRUNETTA, Alberto; CIGALES, Marcelo. Dossiês sobre ensino de sociologia no Brasil (2007-2015): temáticas e autores(as). Revista Latitude, Maceió, v. 12 , n. 1, p. 148-171, 2018.

CIGALES, Marcelo P. A sociologia católica no Brasil (1920-1940): análise dos manuais escolares. 313f. Tese, Programa de Pós-graduação em Sociologia Politica. Universidade Federal de Santa Catarina. Florianópolis, 2019.

CIGALES, Marcelo; FRANKE, Felipe; DALLMANN, Matheus. História e sentidos pedagógicos da Sociologia no Brasil. In: BODART, C; LIMA, W. (Orgs.). 0 ensino de Sociologia no Brasil. v.1. Editora Café com Sociologia, Maceió. 2019, p. 11-32.

DURKHEIM, Émile. Educação e Sociologia. Tradução de Lourenço Filho. 5. ed. São Paulo: Edições Melhoramentos, s.d.

ELIAS, Norbert. O processo civilizador: formação do Estado e Civilização. v.2. Rio de Janeiro: Zahar, 1993.

GALLO, Sílvio. Metodologia do ensino de filosofia: uma didática para o ensino médio. Campinas: Papirus, 2016.

GESTEIRA, Beatriz Muniz. Os discursos ideológicos sobre a inclusão da sociologia nas tramitações dos projetos de lei 3. 178/1997 e 1. 641/2003. In: MAÇAIRA, Julia; FRAGA, Alexandre (Orgs.). Saberes e práticas do ensino de sociologia. Rio de Janeiro: Autografia, 2018, p. 135-161.

KATREIN, Camila Siqueira; MARCASSA, L. P. . Assédio moral no cenário de precarização e desprofissionalização da educação pública. In: José Antônio Peres Gediel; Lawrence Estivalet de Mello; Fernanda Zanin; João Luiz Arzeno da Silva. (Org.). Estratégias autoritárias do Estado empregador. 1ed. Curitiba, PR: Kaygangue Ltda, 2017, p. 133-153

LENNERT, Ana Lúcia. Condições de trabalho do professor de sociologia. Cad. Cedes, Campinas, vol. 31, n. 85, p. 383-403, set.-dez. 2011.

SILVA, Ileizi; Gonçalves, Danyelle. (orgs). A sociologia na Educação Básica. Annablume: Pinheiros/SP, 2017.

RÊSES, Erlando. E com a Palavra: Os Alunos - Estudo das Representações Sociais dos Alunos da Rede Pública do Distrito Federal sobre a Sociologia no Ensino Médio. Dissertação (Mestrado em Sociologia). Instituto de Ciências Sociais da Universidade de Brasilia, Distrito Federal, 2004.

RÊSES, Erlando. A Vez e a Voz dos Alunos. In: RÊSES, Erlando; SANTOS, Mário Bispo dos; RODRIGUES, Shirlei Daudt. A sociologia no ensino 
Os sentidos do ensino de Sociologia: o que dizem egresso/as da licenciatura em Ciências Sociais da UFSC | Marcelo Cigales, Inaê label Barbosa, Sabrina de Freitas Smialoski e Beatriz Melchioretto Claudino dos Santos

médio: cidadania e representações sociais de professores e estudantes. Belo Horizonte: Fino Traço, 2016, p. 87-128.

RÊSES, Erlando; SANTOS, Mário Bispo dos; RODRIGUES, Shirlei Daudt. A sociologia no ensino médio: cidadania e representações sociais de professores e estudantes. Belo Horizonte: Fino Traço, 2016.

SANTOS, Mário. O que pensam os professores? In: RÊSES, Erlando; SANTOS, Mário Bispo dos; RODRIGUES, Shirlei Daudt. A sociologia no ensino médio: cidadania e representações sociais de professores e estudantes. Belo Horizonte: Fino Traço, 2016, p. 39-86.

SANTOS, Mário Bispo. Diretrizes curriculares estaduais para o ensino de sociologia: em busca de um mapa comum. PerCursos, Florianópolis, v. 13, n. 1, p. 40-59, 2012.

OLIVEIRA, Amurabi. O ensino de Ciências Sociais na Faculdade Catarinense de Filosofia. Ciências Sociais Unisinos, São Leopoldo, v. 54, n. 1, p. 117 $125,2018$. 